\title{
Research in the Temperature Effect of Corrugated Steel Webs Combined Bridge
}

\author{
Honglin $\mathrm{Ma}^{1, \mathrm{a}}$, Xiaoyan $\mathrm{Liu}^{2, \mathrm{~b}}$, Chen $\mathrm{Yao}^{3, \mathrm{c}}$, ${ }^{*}$ Yuan $\mathrm{Cao}^{3, \mathrm{~d}}$ \\ ${ }^{1}$ Transportation Department of Ningxia Hui Nationnality Autonomous Region, \\ Yin Chuan, Ningxia 750000 China; \\ ${ }^{2}$ School of Civil Engineering and Architecture, Changsha University of Science and Techology, \\ Changsha, Hunan 410014,China \\ ${ }^{3}$ Geotechnical and Structural Engineering Research Center of Shandong University, \\ Jinan, Shandong, 250061 China \\ a9940247134@qq.com, b373595817@qq.com, '1270695133@qq.com , d240895091@qq.com
}

Keywords: corrugated steel web; combined bridge; temperature test; temperature gradient mode

\begin{abstract}
It is necessary to research the temperature field because corrugated steel web PC combined box girder is made from different material in the roof, floor and web, and temperature distribution in the sunshine is also different. This paper relies on a flyover as the actual engineering background, combing with theory, and comes up with two kinds of distribution patterns of temperature field of this bridge by analyzing data obtained by collecting for 90 days in 32 measuring points of this bridge.Under the influences of sunlight, the temperature of corrugated steel webrises rapidly above the concrete roof and floor and its distribution is a special form. In the night, the temperature of corrugated steel web drops rapidly below the concrete roof and floor and its distribution is a vertical $\mathrm{C}$-shaped. And fit sunshine temperature gradient mode suitable for the corrugated steel web PC combined box bridge in Guanzhong area. There is a reference meaning for similar bridges.
\end{abstract}

\section{Introduction}

In order to reduce the weight of the bridge and improve efficiency in the use of prestressed and shear strength, more and more bridges using corrugated steel web instead of traditional concrete web, it is using corrugated steel web PC combined box girder with unique structure form. Such a bridge is made up of concrete roof, floor and corrugated steel web. Difference of two kinds of material results in different temperature effects. Steel thermal conductivity is good, which has a more sensitive reaction to ambient temperature. In contrast, concrete thermal conductivity is poor, which has a slow response to the ambient temperature. The two kinds of material make a different temperature distribution between concrete roof, floor and corrugated steel web. Since the 50s of last century, domestic and international scholars had a recognization that the importance of temperature on the bridge structure, and began study it, but mainly in the concrete bridge, less in this corrugated steel web PC combined box girder. Therefore, it is necessary to research the temperature effects of the structre of corrugated steel web PC combined box girder.

Temperature load usually acts as the form of temperature field which passes to structure with sunshine changing, however, you must first obtain the temperature load before researching the temperature effects of corrugated steel web PC combined box girder. So, the key of researching temperature effects is that solving accurate and reliable temperature field.

This paper takes a flyover as the actural engineering background, and makes an actual long-term continuous observation on its box girder sectional temperature which is based on solar radiation environment. Choose the most adverse effect temperature distribution on the structure from a variety of complex temperature distribution. And then explore the temperature field adaptating to Guanzhong area and work out the temperature gradient pattern. 


\section{Engineering Background}

The flyover situates in the Guanzhong Plain, located in Xi'an, Shaanxi Province, which belongs to a sub-humid warm tropical continental monsoon climate region and has marked cold-warm and dry-humid at all seasons. The annual average temperature is 13.5 degrees, the highest temperature is up to 43.0 degrees and the extreme minimum temperature is -16.9 degrees.

The upper part of the east-west bridge is $2 \times 30$ meters corrugated steel web PC combined cast-in-place continuous box girder, the lower part of it consists of column pier, pile-column table, cast-in-situ bored pile. The deck width is $8 \mathrm{~m}$. The main girder adopts box-section and takes corrugated steel web as inclined web. The bridge adopts two-way prestress: a longitudinal prestressed beam is divided into vivo and vitro bundles. The vivo bundles uses 270 degrees $\Phi$ s15.2 low relaxation prestressed beams and its tensile strength standard value is fpk $=1860 \mathrm{MPa}$; The vitro bundles takes 270 degree $\Phi$ s15.2 low relaxation epoxy coating prestressed beams and its tensile strength standard value is fpk=1860MPa.

\section{Field Test}

In order to better reflect the temperature distribution of box girder in every direction, select junction between 0 \# and 1 \#, two box girder section away from $10 \mathrm{~cm}$, as the temperature observation plane in which measuring points are arranged shown in Figure 1. There are 32 measuring points. Observation time is between 2015.3.28 and 2015.6.27, a total of 90 days.

In the process of temperature observation, the ambient temperature and the structure temperature are constantly changing. In order to grasp the temperature field distribution of th section and its variation regular, it needs time-sensitive as data collection and ensures that all data is simultaneously measured. Therefore, using JMZR-2012 model wireless temperature transmission system to test which automatically collects data once every two hours to ensure accurate and reliable data. Field sensors embedded and wireless transmission system is shown in Figure 2.
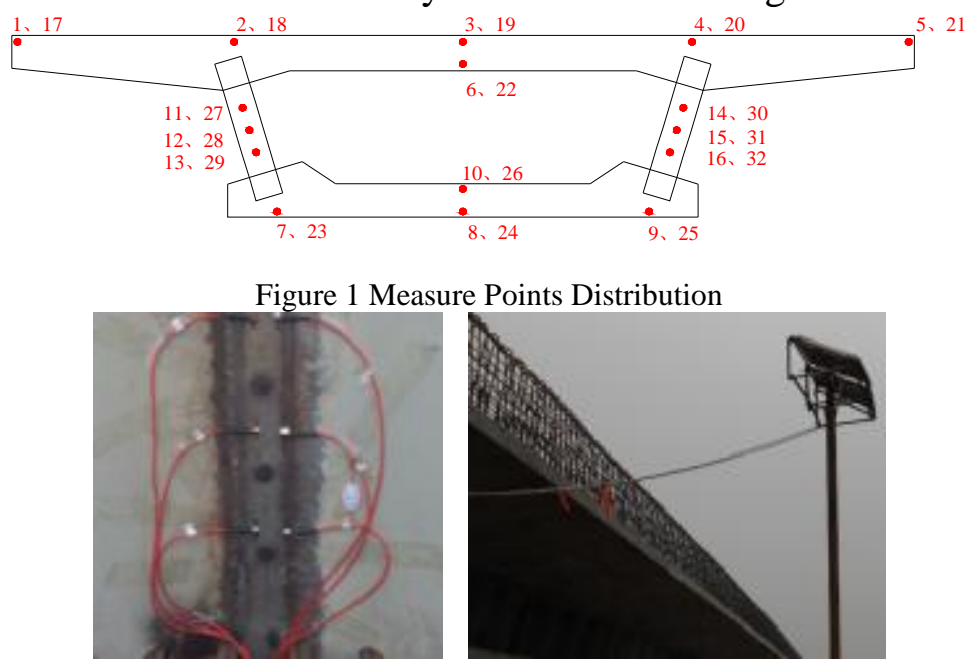

Figure 2 Field Test

\section{Test Data}

Take an average temperature of 12 different test times obtaining by averaging the test temperature of 10 measure points on the roof in 90days as the roof's temperature. Regard temperature average of each six measure points on left and right ventral plate in 90 days as ventral plate's temperature. Average the six measure points on the floor in 9 days as floor's temperature. Overall temperature time-histories changed diagram are shown in Figure 3. 


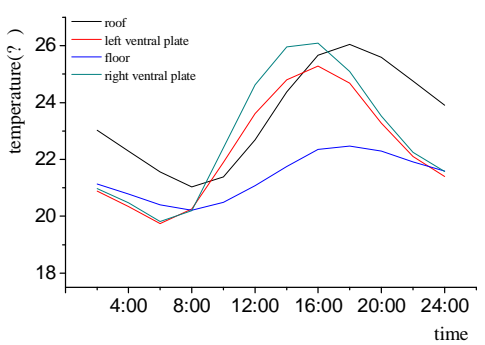

Figure 3 Overall temperature time-histories changed diagram

Research the left and right ventral plates respectively along the beam depth, and average the roof and floor temperature at that time. The vertical changed temperature diagram are shown in Figure 4.
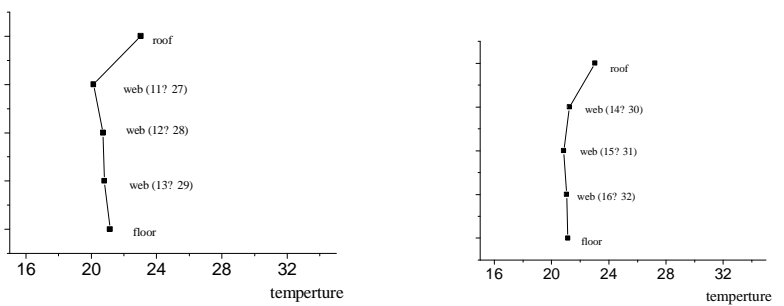

(a) 2:00
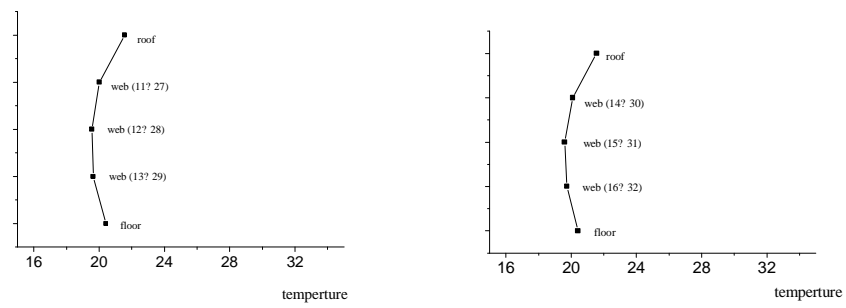

(c) 6:00
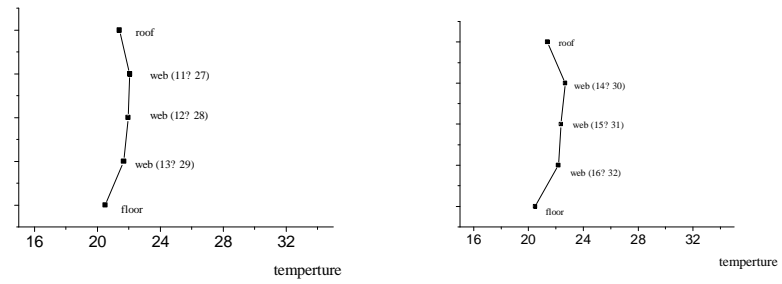

(e) 10:00
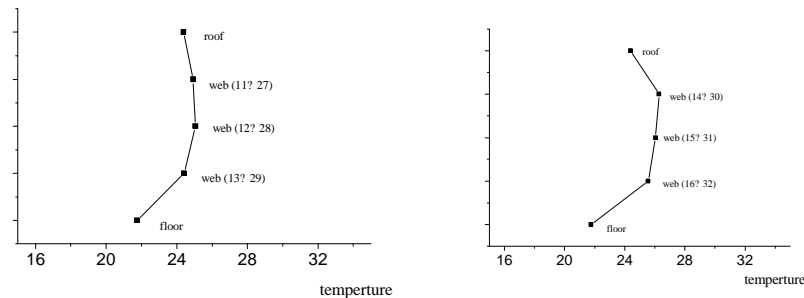

(g) 14:00
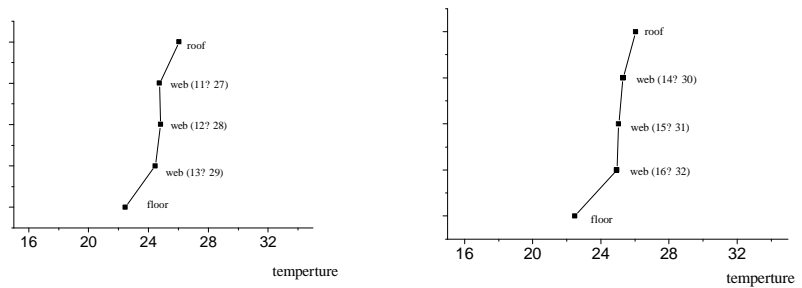

(i) 18:00 

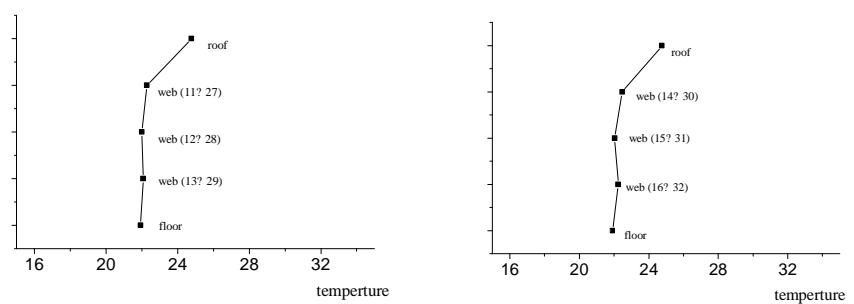

(k) 22:00

Figure4 Vertical Changed Temperature Diagram at Different Times

\section{Data Analysis}

Figure 3 is a temperature changed process curve of roof, ventral plate and floor. As can be seen from the figure, the temperature distribution of these three plates varies at different times from morning 6:00 when temperature gradient is ever-increasing to PM 16: 00-18: 00 reaching the maximum. And then it begins to decrease until 6:00 in the next morning to return to a minimum. According to the average, overnight $(24 \mathrm{~h})$ is approximate to sinusoidal function. Because sunshine has a greater influence on roof, the roof temperature is higher than the floor's and changes greater than the floor's. Compared with the concrete roof and floor, temperature change of corrugated steel web is more intense, the reason is that thermal performance of steel is better than concrete.

Figure 4 is a vertical temperature distribution diagram measured at different time points. As can be seen from it, there are two kinds of corrugated steel web PC combined bridge vertical temperature fields: Under the inflence of sunlight, from 6:00 to 18:00 the temperature of corrugated steel web rises rapidly above the concrete roof and floor and its distribution is a special form. From 18:00 to the next morning 6:00 has no sunlight influence, the temperature of corrugated steel web drops rapidly below the concrete roof and floor and its distribution is a vertical C-shaped.

As can be seen in combination with Figure 3, the temperature peak appears at 16:00, and valley appears at 6:00, while the maximum temperature difference between daytime and night also appears in these two time points. Therefore, choose 16:00 and 6:00 temperature distribution as the focus researching temperature field which is the most unfavorable during the day and night, which is designed to control the required temperature load. Thereby determine the temperature gradient pattern of corrugated steel web PC combined bridges adapted to the Guanzhong area.

Now we think the corrugated steel webs temperature is approximately uniform by taking advantage of mathematical statistical methods. The most unfavorable vertical temperature gradient of corrugated steel web PC combined box girder (along the beam depth) is shown in Figure 5 and Figure 6. In the two figures, take webs temperature as reference temperature and $\mathrm{h}$ as beam depth.

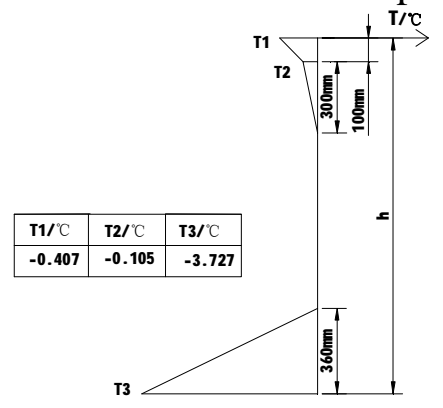

Figure 5 Vertical temperature gradient pattern in daytime 


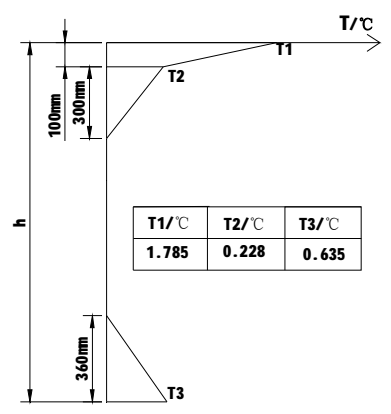

Figure 6 Vertical temperature gradient pattern in night

Above-mentioned box girder temperature gradient pattern is similar to the rule of "vertical temperature gradient pattern" in our new "highway bridge design general specification (JTGD60-2004)".However, there is something different, on the one hand, the bottom of the beam in certain extent has no temperature in highway bridge design specification, which is unreasonable, on the other hand, the temperature difference between roof and floor is smaller than it in specification, the reason is that width of the bridge is small and ventral wet is corrugated steel with a good thermal conductivity.

In addition, the current specification does not consider different kinds of climate crossing the country and use the same temperature mode regardless of where it is, while the climate of the whole country varies greatly, undoubtedly, it will have remarkable error if analysing according to the same temperature pattern. Therefore, it is critical to research and choose temperature field, only by determing a reasonable temperature field, can make a further research and analysis to temperature effects issues correctly.

\section{Conclusion}

1) Although it has temperature difference at the roof and floor measured points in sideways at different times, temperature difference is smaller exclude exceptional days. So we can think the lateral temperature is uniformity of concrete roof and floor, for which the bridge lateral width is small.

2) It can be seen from Figure 3, according to the average, the temperature distribution of roof, ventral web and floor is approximate to a sine function day-night. But its peak is different and times reaching to peak also vary slightly.

3) As can be seen from Figure 4, the vertical temperature field of corrugated steel web PC combined bridge has two kinds: Under the inflence of sunlight, the temperature of corrugated steel web rises rapidly above the concrete roof and floor and its distribution is a special shaped. In the night, the temperature of corrugated steel web drops rapidly below the concrete roof and floor and its distribution is a vertical C-shaped.

4) To the most unfavorable temperature of corrugated steel webs combined bridge, fitting two kinds of temperature fields for day and night by mathematical statistical method. Identifying the temperature pattern of corrugated steel web combined bridge adapted to the Guanzhong area, which lays foundation for the calculation and analysis of the temperature effect.

\section{Acknowledgement:}

Supported by Natural Science Foundation of Hunan Province of China（11jj5031）.

\section{References}

[1] Guo Xiangfei.Research in the Temperature Effect of Corrugated Steel Webs Prestressed Concrete Box Girder [D] Chang An University, 2011.

[2] Reference to a chapter in an edited book: Liu Yuqing.Structral System Analysis of Corrugated Web Combined Box [J].Bridge Engineering, 2005, (1):1-4 
[3] Liu Xingfa.Analysis of Temperature Stress in Concrete Structure [M].Bei Jing:China communication press, 1991: 2-89.

[4] Zhu Pengzhi.Studies on Special Bridge Structures Temperature Problem[D].Hang Zhou: Zhejiang University,2008.

[5] Ge Yaojun,Zai Dong,Zhang Guoquan.The Research on Temperature Field of Concrete cable-stayed bridge [J].China Journal of Highway1996,9(2):76-831.

[6] Sun Quansheng,Fu Keqi.Research on Temperature Influence of Sui Fenhe Cable-stayed Bridge with Swivel Erection [J].Highway Traffic Scientific and Technology,2006,23(10):55-59.

[7] Ye Jianshu,Jia Lin,Qian Peishu.Observation and Analysis on Temperature Distribution of PC Box Girder Bridges [J].Jornal of Dong Nan University (Natural Science),2002 (5):788-7931.

[8] Zhang Xiedong,Cai Sujun,Shi Mingqiang.Observation and Analysis on Temperature Field of Concrte Box Girder Bridge[J].Highway Traffic Scientific and Technology,2008,25(10):52-57.

[9] Xia Wanhui.Research on Temperature impacts on PC Continuous Beam Bridge test-Stress [J].Traffic Scientific and Technology,2004(6):1-31.

[10] JTGD60-2004, General Code for Design of Highway Bridge and Culvert[S].2004.

[11] She Xiaonian, Fang Zhi, Wang Jian,etc. Temperature Gradient Analysis of Long-span Prestressed Concrete Box-girder Bridge [J].Highway, 2003(11):135-1381.

[12] Guo Jian. Analysis on Unsteady State Temperature Field and Prestress Field of Beam of concrete Cable-stayed Bridge[J].China Journal of Highway,2005,18(2):65-681. 